This document was prepared in conjunction with work accomplished under Contract No. DE-AC09-96SR18500 with the U.S. Department of Energy.

This work was prepared under an agreement with and funded by the U.S. Government. Neither the U. S. Government or its employees, nor any of its contractors, subcontractors or their employees, makes any express or implied: 1 . warranty or assumes any legal liability for the accuracy, completeness, or for the use or results of such use of any information, product, or process disclosed; or 2 . representation that such use or results of such use would not infringe privately owned rights; or 3 . endorsement or recommendation of any specifically identified commercial product, process, or service. Any views and opinions of authors expressed in this work do not necessarily state or reflect those of the United States Government, or its contractors, or subcontractors. 
Proceedings of the $11^{\text {th }}$ International Conference on Environmental Remediation and Radioactive Waste Management

ICEM2007

September 2-6, 2007, Oud Sint-Jan Hospital Conference Center, Bruges, Belgium

ICEM07-7369

\title{
UTILIZING THE RIGHT MIX OF ENVIRONMENTAL CLEANUP TECHNOLOGIES
}

\author{
Wade Whitaker \\ United States Department of Energy \\ Bldg. 730-B, Aiken, SC 29808 \\ wade.whitaker@srs.gov \\ Chris Bergren \\ Bechtel Savannah River Incorporated \\ Bldg. 730-4B, Aiken, SC 29808 \\ chris.bergren@srs.gov \\ Mary Flora \\ Washington Savannah River Company \\ Bldg. 730-4B, Aiken, SC 29808 \\ mary.flora@srs.gov
}

\begin{abstract}
The Savannah River Site (SRS) Figure 1 is a 310-square-mile United States Department of Energy nuclear facility located along the Savannah River near Aiken, South Carolina. During operations, which started in 1951, hazardous substances (chemicals and radionuclides) were released to the environment. The releases occurred as a result of inadvertent spills and waste disposal in unlined pits and basins which was common practice before environmental regulations existed. The hazardous substances have migrated to the vadose zone and groundwater in many areas of the SRS, resulting in 515 waste units that are required by environmental regulations, to undergo characterization and, if needed, remediation. In the initial years of the SRS environmental cleanup program (early 1990s), the focus was to use common technologies (such as pump and treat, air stripping, excavation and removal) that actively and tangibly removed contamination. Exclusive use of these technologies required continued and significant funding while often failing to meet acceptable clean-up goals and objectives. Recognizing that a more cost-effective approach was needed, SRS implemented new and complementary remediation methods focused on active and passive technologies targeted to solve specific
\end{abstract}

remediation problems. Today, SRS uses technologies such as chemical / pH-adjusting injection, phytoremediation, underground cutoff walls, dynamic underground stripping, soil fracturing, microbial degradation, baroballs, electrical resistance heating, soil vapor extraction, and microblowers to more effectively treat contamination at lower costs.

Additionally, SRS's remediation approach cost effectively maximizes cleanup as SRS works proactively with multiple regulatory agencies. Using GIS, video, animation, and graphics, SRS is able to provide an accurate depiction of the evolution of SRS groundwater and vadose zone cleanup activities to convince stakeholders and regulators of the effectiveness of various cleanup technologies. Remediating large, complex groundwater plumes using state of-the art technologies and approaches is a hallmark of years of experience and progress. Environmental restoration at SRS continues to be a challenging and dynamic process as new cleanup technologies and approaches are adopted.

\section{BACKGROUND}

After 40 years of producing nuclear materials for defense and non-defense uses, the Department of Energy (DOE) shifted its strategic direction and 


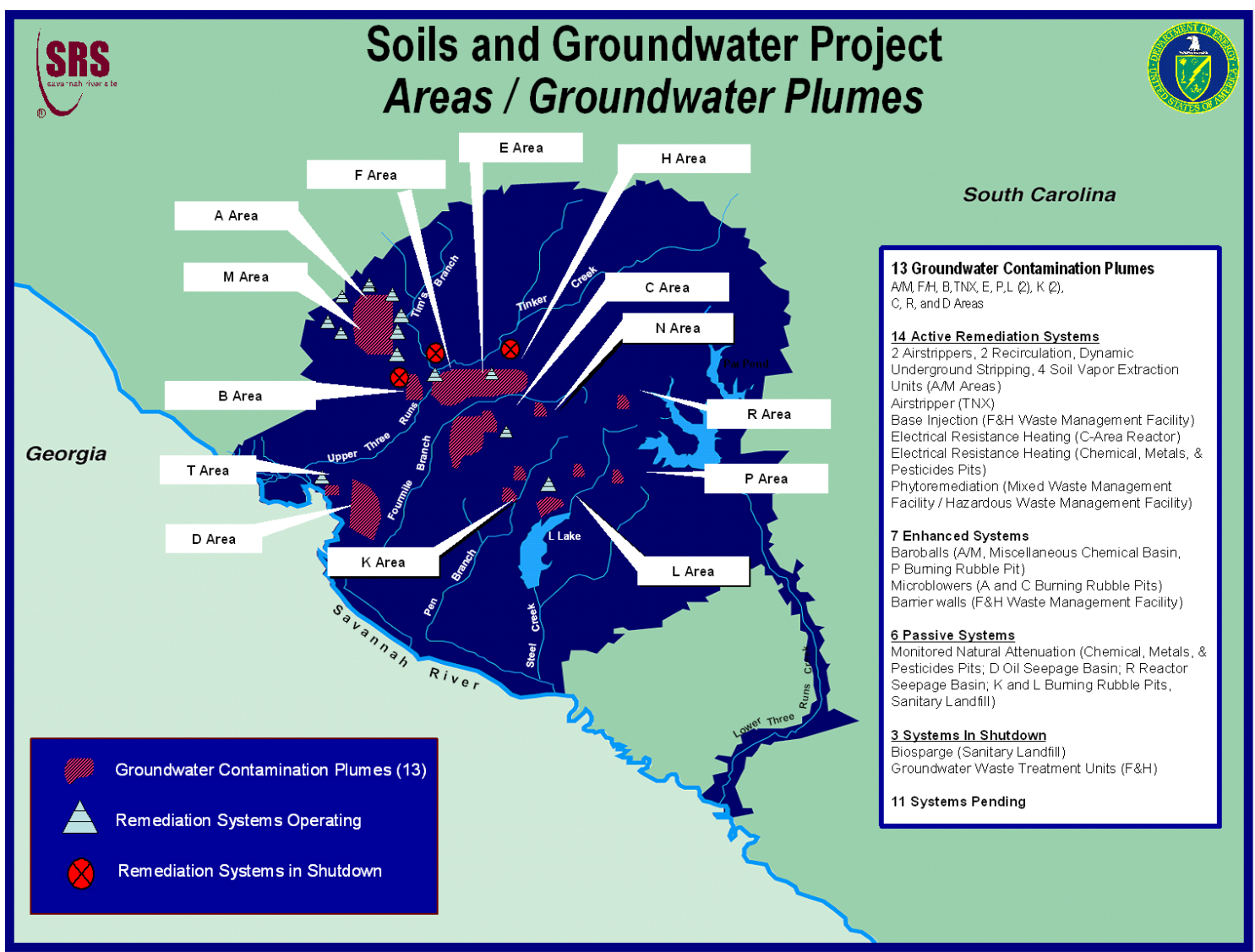

Figure 1

resources from nuclear materials production to the cleanup of the nuclear waste and environmental contamination created during production. The start of the environmental restoration program at the Savannah River Site (SRS) began in 1981 when the site began inventorying waste units. Since then, DOE has established a successful environmental restoration program that is focused on the cleanup of soils (including vadose zone), surface water and groundwater contamination. SRS has identified 515 waste units, which include surface waste sites, groundwater and surface water. The Soils and Water Remediation Project is responsible for cleaning up these waste units to reduce risk and protect human health and the environment. Waste units range in size from a few square feet to tens of acres and include basins, pits, piles, burial grounds, landfills, tanks, and associated groundwater contamination. Remediation of the waste sites and groundwater is regulated under federal and state environmental laws, including the Resource Conservation and Recovery Act (RCRA) and the Comprehensive Environmental Response, Compensation, and Liability Act (CERCLA).
The SRS RCRA permit includes provisions for addressing releases from hazardous waste management facilities and solid waste management units.

In 1993, the Department of Energy (DOE), the Environmental Protection Agency (EPA), and the South Carolina Department of Health and Environmental Control (DHEC) entered into an agreement that describes how the SRS will disposition its inventory of waste units. The $S R S$ Federal Facility Agreement (FFA) was negotiated to ensure SRS cleanup satisfies CERCLA and RCRA requirements.

Early environmental remediation efforts focused on cleaning up contaminated groundwater and lower risk surface units using tried and true technologies. The early surface units were typically located in remote areas of the SRS; the rationale for focusing on individual, remote waste units was two-fold: first, DOE and the regulators were able to gain experience and optimize the cleanup process before addressing more complicated contamination areas and secondly, many of the industrial areas of SRS were still operational, hindering accessibility 
to the waste units, as well as creating occupational risks for those personnel who worked in the vicinity of the units.

As SRS reactor and nuclear materials missions were completed and operations in industrial areas ceased, SRS began addressing waste units in the industrial areas. Significant improvements in the cleanup process appear to be possible if multiple units are addressed simultaneously in each industrial area.

Subsequently, in May 2003, the Department of Energy, the US EPA and SCDHEC signed a Memorandum of Agreement (MOA) to support accelerated cleanup of the SRS using an Area Completion strategy for cleanup. The FFA and cleanup milestones were renegotiated to support the Area Completion strategy.

Under the Area Completion strategy, SRS uses an Area Operable Unit (AOU) concept which integrates D\&D activities and soil and groundwater characterization, assessment, and remediation activities in each of the 14 SRS industrial areas. This strategy focuses on addressing contaminated surface units and the vadose zone, and addressing groundwater plumes subsequently. Groundwater plumes are addressed as separate operable units, and, where possible, consolidated to support more efficient monitoring networks and remedial actions.

\section{GROUNDWATER STRATEGY}

The SRS groundwater strategy specifically addresses groundwater protection concerns through the remediation of groundwater and associated source units. Early recognition of groundwater contamination and the complexity of assessment and remediation brought about a need to phase the overall groundwater effort. As early actions were taken in stepwise increments to achieve efficiencies in clean up, management of the remedial effort also needs to be taken in a phased approach. As a consequence, an SRS groundwater strategy was developed to optimize the balance between assessment and remediation.

The strategy recognizes the dynamics of a source-to-groundwater system. It focused the initial phases of action toward learning about the contaminants, the release points, and the optimal locations for early deployment of cleanup technologies. Since no single technology is going to remedy SRS groundwater, the strategy is to aggressively address the highest concentrations of contaminants accomplishing the highest possible mass removal. Characteristic of the treatment technology is high capital and operational costs, but with high return on contaminates removed (Figure 2). Also in this initial phase, work is performed to close off all original contaminant release points.

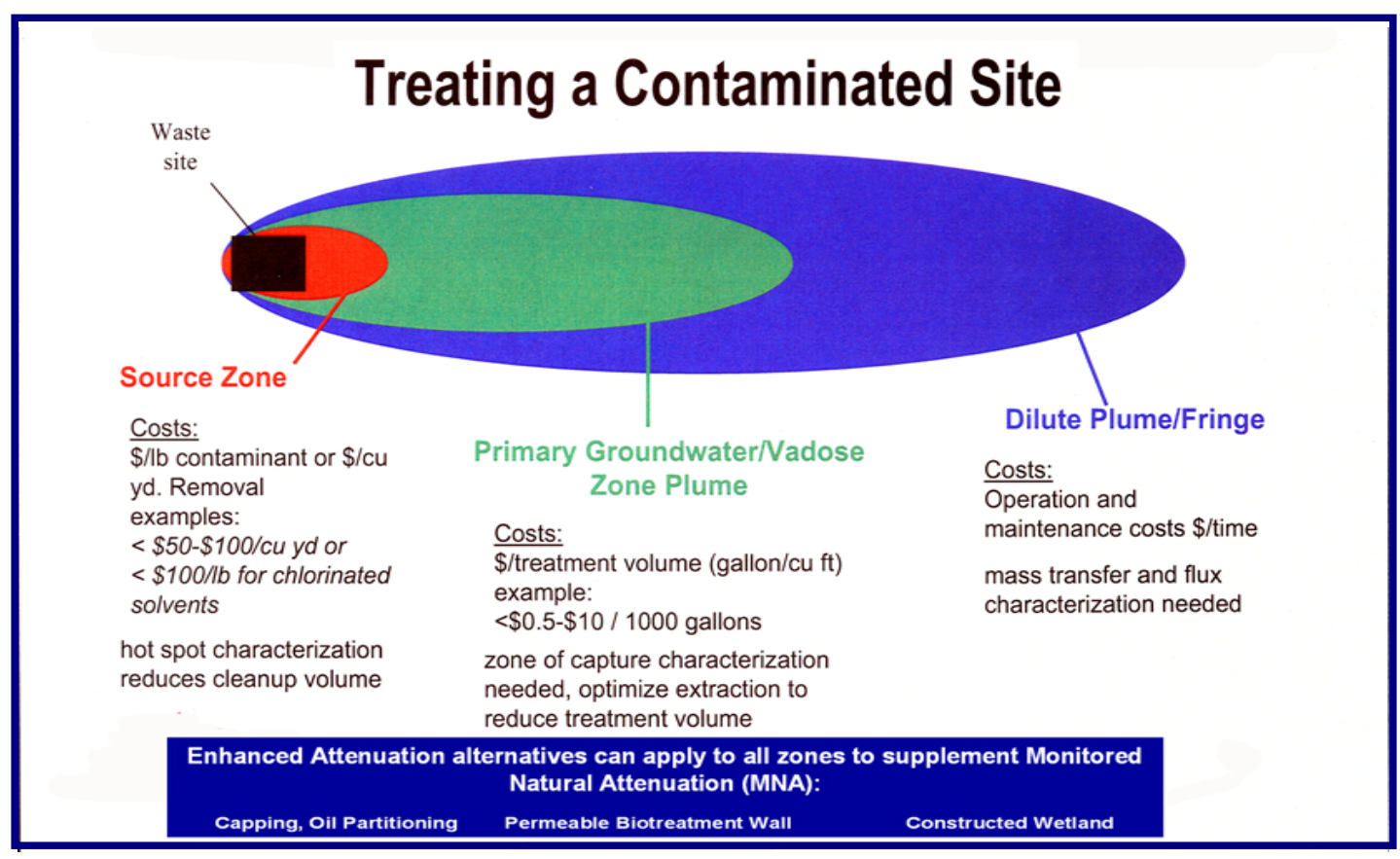

Figure 2 
Technologies associated with low concentration groundwater contamination are also available for final cleanup of dilute/distal plume fringes employing polishing actions after significant mass removal (if necessary) has taken place at the source. Attributes of these low energy treatment technologies would be very low capital and operating cost with easy installation and minimal maintenance.

The common denominator in the strategy of technology selection for differing plume conditions is to match the cost and effectiveness for mass removal with the relative concentration, that is, the opportunity for mass to be removed. A measure of successful technology selection would be that the cost per unit of contaminant removed is low in all phases, and relatively equal.

\section{REMEDIATION SELECTION}

As cleanup challenges have become more complex, the technology selection process has evolved. SRS used standard remediation techniques, such as pump and treat and excavation early in the cleanup program. Since that time, SRS, with regulator approval, has customized remediation approaches to more appropriately address contamination problems.

For instance, SRS has adopted and adapted technologies used in other industries to address remediation challenges. In the oil and gas industry, fracturing soil and rock is commonly used to maximize oil and gas production from tight formations. SRS is taking this same technology to "capture and remove" solvents that are trapped in soil formations.

Another example of technology evolution is the use of enhancements (such as vegetable oil) to promote natural attenuation microbial processes in the subsurface. SRS is currently testing different technologies for accelerating solvent clean up in both saturated and unsaturated media.

Technology selection for the initial installation, or the later replacement of a system, should be made in order to achieve overall remediation at some relatively constant and low cost per unit of contaminant mass treated. Continuing emphasis is placed on developing and implementing alternative remediation technologies. A major goal is transitioning from active remediation systems to passive processes as contaminant concentrations decrease.
Technology selection is important for groundwater remediation. In some cases, existing technologies are prohibitively expensive for long-term use and in other cases the knowledge and technology needed to address the problem does not yet exist. High concentration contaminant source areas typically warrant aggressive remedial technologies while less aggressive technologies may be more appropriately utilized down gradient in the primary groundwater plume. The dilute plume is more appropriately addressed with low energy technologies. This graded approach addresses the three significant components of a contaminated plume.

Figure 2 summarizes the costs of different technologies in place, ranging from active through passive and locations where cleanup has been achieved. Noted below are some examples source to passive remedial technologies employed at SRS

\section{Source remediation systems}

Electrical Resistance Heating (ERH) Systemremedial action using ERH system all but eliminated the source of groundwater contamination in the vadose zone at the SRS' CReactor Area. About 99\% of the original solvent, trichloroethylene (TCE) mass (730 pounds) was removed within the 3 months of operation. The recently completed action has proven to be outstanding in the removal of TCE from the area's groundwater waste unit, meeting regulatory stipulated cleanup goals.

ERH is a soil treatment technology used to remediate solvent contamination in the vadose zone. Electrodes inserted into the subsurface heat the soil to 200 degrees Fahrenheit, transforming the liquid solvents into a gas phase. The contaminants are removed from the soil using soil vapor extraction. The rate of removal has proven to be over 80 percent faster than conventional soil vapor extraction alone. The equipment has been redeployed at another SRS waste unit for use in that cleanup effort.

High rate of success was achieved with the deployment and operation of the ERH System because solvent sources retained in the subsurface clay / silt layers are difficult to remove with conventional soil vapor extraction alone. The ERH system facilitates quick and easy capture and destruction of solvent contamination, not only expediting SRS cleanup, 
but also preventing further impact to the groundwater aquifers.

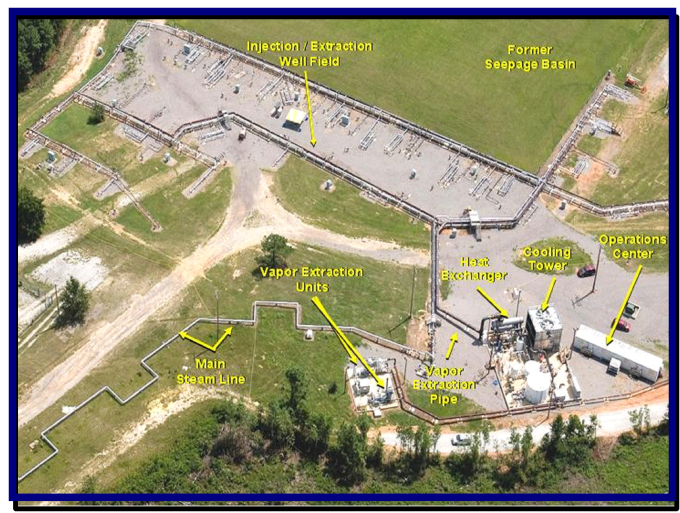

Figure 3

Dynamic Underground Stripping (DUS) SystemThe SRS has made significant progress in remediating a large source of solvents generated from a production area on site, utilizing a process referred to as DUS (Figure 3). The DUS system is an innovative technology that involves steam injection into sandy layers to volatilize subsurface contaminants so they can be extracted with soil vapor extraction units. DUS began operations in August 2005 and has thus far removed over 355,000 pounds of Dense NonAqueous Phase Liquid (DNAPL); the majority of the contaminant being tetrachloroethylene (PCE).

The steam is provided from an existing power plant in the vicinity. The treatment area covers over 3 acres in size and is divided into four parcels to allow a systematic approach to remediation. The four parcels have been heated to 200 degrees Fahrenheit. Because DUS technology extracts solvent vapor 15 times faster than Soil Vapor Extraction and 75 times faster than pump-and-treat systems, over six decades of pump and treat remediation is estimated to be avoided at the SRS M-Area Settling Basin.

The DUS system offers a significant improvement over baseline processes by greatly increasing cleanup rates and efficiency, and by gaining tight control over the process. Continuous modification of the rate and location of steam flow at several injection wells fosters a more direct migration of product towards the extraction wells and helps prevent both horizontal migration of solvents outside of the steam zone and vertical migration into deeper aquifers.
The DUS technology made its debut at SRS in 2000 when its deployment successfully remediated 70,000 pounds of VOC's in a single year at the 321-M Solvent Storage Tank Area.

\section{Passive remediation systems}

Phytoremediation Process- SRS and the regulators have recognized that in some cases, actively removing contamination is not practicable from a cost and/or time perspective. For instance, active treatment to remove tritium from the groundwater is prohibitively expensive and can take decades.

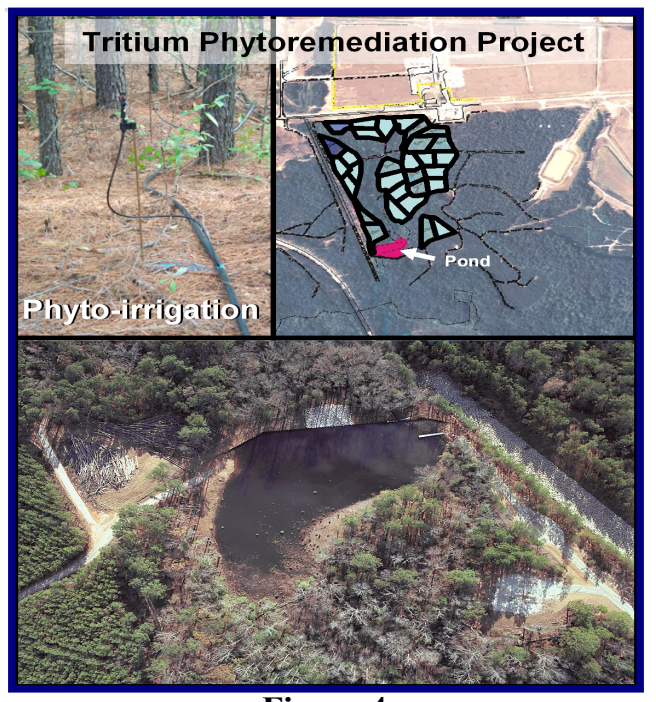

Figure 4

However, at the Mixed Waste Management Facility (Figure 4), tritium contaminated groundwater was seeping into a surface stream creating an unacceptable risk. For this reason, SRS, with regulator approval, developed a lowcost, passive yet very effective approach to minimize the migration of tritium into the surface water. SRS constructed a retention pond with sheet pile at the seepline to collect the tritium-contaminated water. This water is then pumped upgradient through common piping material and used to irrigate native vegetation. This phytoremediation process remediates tritium simply and naturally without constructing expensive treatment facilities.

Barrier Walls and Base Injection - Another passive remediation approach being used at SRS addresses metal and radionuclide contamination in the groundwater near $\mathrm{F}$ and $\mathrm{H}$ Areas. These plumes containing tritium and metals were outcropping into a surface stream within the SRS 
boundary. To address the contamination, SRS originally constructed two pump and treat facilities designed to remove contamination from extracted groundwater. The facilities were expensive to construct and maintain and operations were only marginally $(<60 \%)$ successful in removing the contamination. A passive system of underground barrier walls coupled with injection of a basic solution was determined to be more effective at treating and managing the contaminated plumes. The barrier walls effectively control the migration of the tritium into the surface streams. The injected base solution adjusts the $\mathrm{pH}$ so the metals adhere to the soil particles, retarding contaminant migration.

Monitored Natural Attenuation (MNA) - MNA is a technology that is being utilized at SRS with and without other remediation systems. MNA is a highly cost-effective approach in which natural processes (microbial, radioactive decay, dilution) are utilized to address vadose zone and groundwater contamination.

Cleanup Progress- Critical to continued regulatory support to utilize new technologies is the SRS ability to clearly depict cleanup progress. Using geographic information system (GIS), video, animation, and graphics, SRS is able to provide an accurate and positive depiction of the evolution of SRS groundwater and vadose zone cleanup activities.

\section{SUMMARY}

The SRS has a mature remediation project with 336 of 515 units having been dispositioned. SRS works closely with multiple regulatory agencies and stakeholders to make remediation decisions commensurate with environmental risks. SRS uses a remediation tool box approach, selecting technologies consistent with remediation goals and objectives. In addition, innovative technologies are employed whenever possible, relying on the concept of aggressive source remediation and passive treatment for distal groundwater plumes / low concentration conditions.

No single technology is appropriate to clean up contaminants found at SRS. Robust cleanup requires a combination of innovative and off-theshelf technologies. When source term contamination is present in significant concentrations, then very aggressive technologies can be rapidly deployed to begin the remediation of the "worst first". As contaminant levels decrease due to successful initial treatment or through the attenuation from plume movement, then less aggressive technologies can be substituted for achieving the mass remediation at lower cost per unit of treatment.

Finally, the regulatory process has to recognize the significance of this strategy with appropriate decision documents supporting its implementation. As is the case at the SRS, this phased approach allows continual improvement of remediation effectiveness through cleanup system optimization 